Article

\title{
Assessing the Impact of Aviation Noise on Housing Prices Using New Estimated Noise Value: The Case of Taiwan Taoyuan International Airport
}

\author{
Hsiu-Chang Tsao ${ }^{1}$ (D) and Chi-Jie Lu ${ }^{1,2,3, *(D)}$
}

1 Graduate Institute of Business Administration, Fu Jen Catholic University, New Taipei City 242062, Taiwan; 408088054@gapp.fju.edu.tw

2 Department of Information Management, Fu Jen Catholic University, New Taipei City 242062, Taiwan

3 Artificial Intelligence Development Center, Fu Jen Catholic University, New Taipei City 242062, Taiwan

* Correspondence: 059099@mail.fju.edu.tw; Tel.: +886-2-29052973

Citation: Tsao, H.-C.; Lu, C.-J. Assessing the Impact of Aviation Noise on Housing Prices Using New Estimated Noise Value: The Case of Taiwan Taoyuan International Airport. Sustainability 2022, 14, 1713. https://doi.org/10.3390/su14031713 Academic Editor: Timothy Van Renterghem

Received: 10 December 2021

Accepted: 28 January 2022

Published: 1 February 2022

Publisher's Note: MDPI stays neutral with regard to jurisdictional claims in published maps and institutional affiliations.

Copyright: (c) 2022 by the authors. Licensee MDPI, Basel, Switzerland. This article is an open access article distributed under the terms and conditions of the Creative Commons Attribution (CC BY) license (https:/ / creativecommons.org/licenses/by/ $4.0 /)$.

\begin{abstract}
Aviation noise at airports has a significant impact on nearby residents' quality of life and residential property values. This study evaluated the impact of aviation noise based on house prices by using three different hedonic price models. Two novel independent noise variables, the estimated aviation noise value and noise reward fund are proposed for constructing effective hedonic price models. The real data of real estate transactions from the region defined by the Taoyuan International Airport's 60-64 dB day-night average sound level ( $\mathrm{Ldn}$ ) and $\geq 65 \mathrm{~dB}$ Ldn noise contours are adopted as empirical data. Empirical results showed that the double-log hedonic price model with the proposed estimated aviation noise variables is the most suitable model for this study. Based on the double-log model, this study found that aviation noise has a significant negative impact on house prices in both noise contour areas of 60-64 dB Ldn and $\geq 65 \mathrm{~dB}$ Ldn. The rate of decline in house prices is approximately USD $2356.02 / \mathrm{dB}$ and USD $3622.78 / \mathrm{dB}$ in the $60-64 \mathrm{~dB} \mathrm{Ldn}$ and $\geq 65 \mathrm{~dB} \mathrm{Ldn}$ contour areas, respectively. Our results also showed that the noise reward fund had no significant impact on the house prices which implies that the current subsidy method has been maintained at an appropriate level for Taoyuan International Airport.
\end{abstract}

Keywords: aviation noise; noise monitoring; noise measurements; real house value registry scheme; hedonic price methods

\section{Introduction}

Environmental noise has been shown to be not only detrimental to physical and psychological health but also affects all aspects of daily life [1,2]. According to the Environmental Noise Guidelines for European Region published by the World Health Organization (WHO), environmental noise may directly induce acute cardiovascular and metabolic effects [3-6]. A study by Tofield demonstrated that residents living in an environment with an average noise value of $50 \mathrm{~dB}$ Lnight over a prolonged period had a $6 \%$ increased risk of developing hypertension compared with a quieter environment of $40 \mathrm{~dB}$ Lnight. Even with a noise disturbance event of $40 \mathrm{~dB}-50 \mathrm{~dB}$, people can change from a state of being fast asleep to semi-fast asleep; whereas $70 \mathrm{~dB}-100 \mathrm{~dB}$ can make people mentally distracted and even cause accidents. Following air pollution, noise pollution has become another major environmental factor that endangers human health [7].

Long-term exposure to aviation noise has also been shown to be associated with the prevalence of arterial hypertension [8]. Ozkurt [9] studied the air traffic data of Izmir Adnan Menderes Airport and found that in $0.3 \%$ of the land area covered by Izmir City center, north of the airport, approximately $2 \%$ of the resident population was exposed to noise levels of $55 \mathrm{~dB}$ day-evening-night noise level (Lden) or higher during day-time and significantly threatened by several illness such as hypertension and sleep disturbances. 
Other studies $[10,11]$ found that according to the health data of more than 1 million people living near Frankfurt Airport, their risk of stroke was $7 \%$ higher than those living in quieter neighborhoods. An analysis of 24,886 cardiovascular deaths between 2000 and 2015 among people living near Switzerland's Zurich Airport saw significant increases in night-time mortality, especially among women. The variety of possible negative effects caused by aviation noise makes it an important topic to explore the effects generated by aviation noise. This study specially points out that aircraft noise events during night may trigger a cardiovascular death within $2 \mathrm{~h}$.

In addition to the direct threat to the physical and psychological health of residents, the impact of aviation noise on the real estate prices around airports is an important reference for assessing its impact on the external environment. Most studies have used changes in property prices as an estimate or measure of the impact of aviation noise. Espey and Lopez [12] used the hedonic price method to estimate the relationship between residential property prices and airport noise in Sparks (NV, USA). The empirical results revealed that there is a statistically significant negative correlation between airport noise and residential property prices, where the average house price in areas with noise level of $65 \mathrm{~dB}$ daynight average sound level ( $\mathrm{Ldn}$ ) is lower than that of equivalent houses in quieter areas. Theebe [13] used spatial autocorrelation techniques to analyze the sales data of more than 100,000 housing transactions in The Netherlands, according to EU regulations for different noise limits. The results demonstrated that traffic noise has an impact on house prices at a 12\% maximum amount of discount. Püschel and Evangelinos [14] estimated the noise annoyance cost around Flughafen Düsseldorf (Germany) by examining rental apartment market data and found that the airport's fee system does not fully cover its aviation noise costs, with rent discounts of $1.04 \%$ per additional decibel of airport noise. Suksmith and Nitivattananon [15] took Suvarnabhumi International Airport (Thailand) as an example to explore the relationship between house prices and airport externality costs; they found that only noise and air pollution are significantly negatively correlated to property values and that noise pollution is more influential to house prices than air pollution. This study agrees that the market value of property losses should be considered when designing compensation schemes. Using the hedonic price method, Bishop and Laing [16] used the hedonic price model to find out that the properties under the flight path of Cairns Airport had a significantly lower value during the period from 2012 to 2016.

The hedonic price model has been widely used in the literature to evaluate the impact of noise or environmental pollution on house prices [17-20]. The earliest study that used the hedonic price model to analyze the impact of environmental pollution on real estate prices was Ridker and Henning, with the aim of determining the impact of air pollution on house prices [21]. Huderek-Glapska and Trojanek [22] used the hedonic price regression approach to estimate the impact of Warsaw Chopin Airport on house prices with a logit model. They compared the prices of the residences located within the limited use area (LUA) of Warsaw Chopin Airport, the biggest airport and the main transfer node in Poland, with that of equivalent residences located outside the LUA, and found that the former were about $1 \%$ cheaper than the latter. In a study by Mense [23] on the impact of the expansion of Berlin Brandenburg International Airport on the price of apartments located under the flight path showed that the flight path substantially affected the noise level. The loss of value of the affected properties was $9.6 \%$ on average within a slant distance of $3 \mathrm{~km}$ from a planned flight path. If the flight altitude is below $1000 \mathrm{~m}$, the price discount is between $11.8 \%$ and $12.8 \%$, whereas for higher flight altitudes, the average decline in prices is estimated to be $8.3 \%$. Trojanek et al. [24] took the residential houses near Lawica International Airport in Poland for the period from 2010 to 2015 as the research subject. Through the hedonic price model, they found strong evidence that the noise depreciation index value is $0.87 \%$ in the case of suites and $0.57 \%$ in the case of apartments. Trojanek and Huderek-Glapska [25] applied the hedonic price model to evaluate the association between the LUA being established on the basis of the actual and predicted noise related to the operation of the Warsaw Chopin Airport and house prices in Warsaw. The results revealed 
that aviation noise is negatively associated with the price value of a dwelling. In a study of the impact of airport operations on real estate prices in the Polish region, Batóg et al. [26] applied spatial hedonic regression and a difference-in-difference approach to address the introduction of new land use restrictions on real estate prices. The results indicated that the introduction of land use restrictions affects real estate prices. Airports in Poland are obliged to limit their environmental impact by creating limited use areas associated with aircraft noise while being responsible for property value loss related to these restrictions. Zheng et al. [27] collected data on housing transactions in residential areas near Hong Kong Kai Tak Airport from 1993 to 2006 to measure the capitalization of noise externality into local house prices. The study confirmed the implicit price of noise pollution, demonstrating that the disappearance of aircraft noise leads to an average increase of $24.43 \%$ in house prices.

Previous literature on the impact of aviation noise on real estate prices has explored zone averages of noise monitoring stations as the main factor, or aviation noise values have not even been discussed as a pattern variable. Because aviation noise recorded at noise monitoring stations is one of the important variables in measuring property prices near airports, the accuracy of the noise values will have a significant impact on the model evaluation results. However, the noise monitoring data in the extant literature are presented as regional averages, which will certainly lead to an underestimation of the effect of real noise values and produce inaccurate or distorted conditions. Because noise monitoring stations are affected by location and distance, the noise values of the residence measured may be different from the actual noise perceived. This study uses the noise reduction formula to estimate the affected noise values of each real estate sample and proposes the estimated aviation noise value as one of the characteristics (explanatory) variables, hoping to reduce disputes among residents near the airport over the assessment of aviation noise.

In addition, most of the existing studies on the impact of aviation noise on real estate prices have only examined the relationship between aviation noise values and property prices and have not discussed the impact of policy subsidies. Moreover, the effect of government compensation is an important factor affecting property prices around airports. Ignoring the effect of policy compensation or subsidies may bias the evaluation results. Noise reward fund is a variable that has not been mentioned in other literature, but in practice it may be an important factor in affecting house prices around airports; therefore, it is also included in this study as a noise attribute variable to analyze the possible effect of policy subsidies on house prices around airports.

This paper aims to investigate the impact of aviation noise on real estate prices in the LUA around airport using the proposed estimated aviation noise value and noise reward fund as the characteristic variables through hedonic price model. We took Taoyuan International Airport as an example to compare the intensity of the impact of different characteristic variables on house prices in the 60-64 dB Ldn and $\geq 65 \mathrm{~dB}$ Ldn aircraft noise contour zones and analyze the impact of each noise attribute on house prices around the airport. The housing transactions outside the noise control zones are excluded in the study. This study performed aviation noise and external cost analyses by primarily using data from airport noise monitoring reports and public house transaction data provided by the government. Thus, the ease of data acquisition made the study results practical and valuable.

The sections of this study include the following: Section 1, Introduction, which explains the motivation and purpose of the study; Section 2, a brief description of aviation noise in Taoyuan International Airport; Section 3, Methods and Data, which defines the variables and data sources; Section 4, Empirical Results; Section 5, Discussion, which analyzes and discusses the important noise attributes in different noise contour zones; and lastly, Section 6, Conclusions, which explains the findings of this study and makes suggestions for follow-up studies. 


\section{Aviation Noise in Taoyuan International Airport}

The aviation market in the Asia-Pacific region has been the world's largest since 2009 [28,29]. Taiwan Taoyuan International Airport (code IATA: TPE, code ICAO: RCTP) is one of the busiest airports in the Asia-Pacific region, with high growth rates of annual carriage of passengers and cargo. The flight movement of passengers at Taoyuan International Airport for 26,498,135 visits in 2010. This increased to over 40 million visits in 2016 and reached $48,360,290$ visits in 2019 . The decadal growth rate is nearly $82.5 \%$. Taoyuan International Airport served more than 250,000 air traffic movements since 2018.

Aviation noise at Taoyuan International Airport has been one of the primary public nuisance issues because of the huge volume of passengers, cargo, and flights. The issue of airport noise compensation and the location of monitoring stations has been repeatedly raised for discussion. The location of automatic noise monitoring equipment directly affects the scope and application of noise compensation. Questions regarding the location of noise monitoring stations in neighboring areas have remained controversial. The measured regional averages of noise monitoring stations are affected by the distance from the house to the station, leading to inconsistencies with the actual noise perception of local residents.

The impact of noise is perceived to be related to the generation and duration of noise. The Ldn is the noise evaluation index, and is based on the US Federal Aviation Regulations, Airport Noise Compatibility Planning (14 CFR Part 150). According to literature [12,30], the price of land and houses will experience a slight discount effect when they are located in the $65 \mathrm{~dB}$ Ldn noise zone. Based on this concept, this research divides the aviation noise area into 60-64 dB Ldn noise contour zone and $\geq 65 \mathrm{~dB}$ Ldn noise contour zone which from $65 \mathrm{~dB}$ Ldn noise contour to the perimeter of airport. The area of 60-64 dB zone is approximately $39.4 \mathrm{~km}^{2}$. The area of $\geq 65 \mathrm{~dB}$ zone is approximately $30.3 \mathrm{~km}^{2}$.

\section{Methods and Data}

\subsection{Hedonic Model}

A house is a physical asset composed of many hidden characteristics; these features may be important factors in determining house prices. The limitation of the hedonic price method is that the features that affect the total house price will vary regionally, and the identification of features by researchers is different; additionally, the marginal effects of the factors affecting the price of housing in each region are different. Therefore, most studies focus on a specific region or market.

This study considers house prices adjusted by aviation noise as the target variable and house price-related variables, and the variables related to the aviation noise area as the characteristic variables. Based on Sherwin Rosen's suggestion to apply different functional methods, this study chooses the optimal function type from semi-log, inverse semi-log, and double-log methods for comparison.

Semi-log method:

$$
\log (y)=\alpha+\sum_{i=1}^{n} \beta x_{i}+\varepsilon_{i}
$$

Inverse semi-log method:

$$
y=\alpha+\sum_{i=1}^{n} \beta \log \left(x_{i}\right)+\varepsilon_{i}
$$

Double-log method:

$$
\log (y)=\alpha+\sum_{i=1}^{n} \beta \log \left(x_{i}\right)+\varepsilon_{i}
$$

In Equations (1)-(3), $y$ is the total house price, $x_{i}$ is the feature, $\beta_{i}$ is the coefficient of the features, $\alpha$ is the intercept of the model, and $\varepsilon_{i}$ is the residual.

\subsection{Variable Definition}

According to the hedonic price theory [31], the selection of variables does not include "general economic factor"; thus, the explanatory variables in this study will be selected 
based on "individual house factor" and "regional environmental factor." Benefield and Sirmans [32] established that structural characteristics, internal and external characteristics of the house, natural environment, neighborhood location, public facilities, market conditions, and financial factor are the most commonly used housing features for house price analysis based on the hedonic price model. However, most house price analysis models use house attributes for analysis, but there are relatively few studies that analyze noise attributes.

Since this research focuses on the analysis and comparison of noise-related factors, the housing features selected from the literature are quantifiable, correlative, and representative. These variables include total floor area, house age, total floor, distance from public markets, distance from high-speed rail (HSR) stations, and distance from airports. Considering noise-related variables, total number of flights $[33,34]$ aviation noise value $[35,36]$ and noise reward fund are three factors that may affect house prices in the noise control zone. The noise reward fund is a variable that has not been discussed in other literature, but may be one of the important elements in practice; additionally, it is one of the noise variables used in this study. The target variable (y), adjusted total price of real estate, and 10 explanatory/independent variables $\left(x_{i}\right)$ used in this study are described as follows:

- The adjusted total price of real estate (ATP):

The interest rate currently listed on the market is the nominal interest rate. The real interest rate is calculated by deducting the inflation rate, usually using the consumer price index (CPI) $[37,38]$. The historical house price trend should be deflated using the CPI to produce real house prices. The data used in this study is sourced from the real estate transaction price inquiry service of the Ministry of the Interior of Taiwan, to obtain the representative real estate prices. The total house prices are based on 2016 prices, and the Taoyuan area house price index of the current season (Figure 1) is used to tackle misjudgment of numerical distortions. This can accurately reflect the market price with improved credibility [39].

- $\quad$ Total flights (TF)

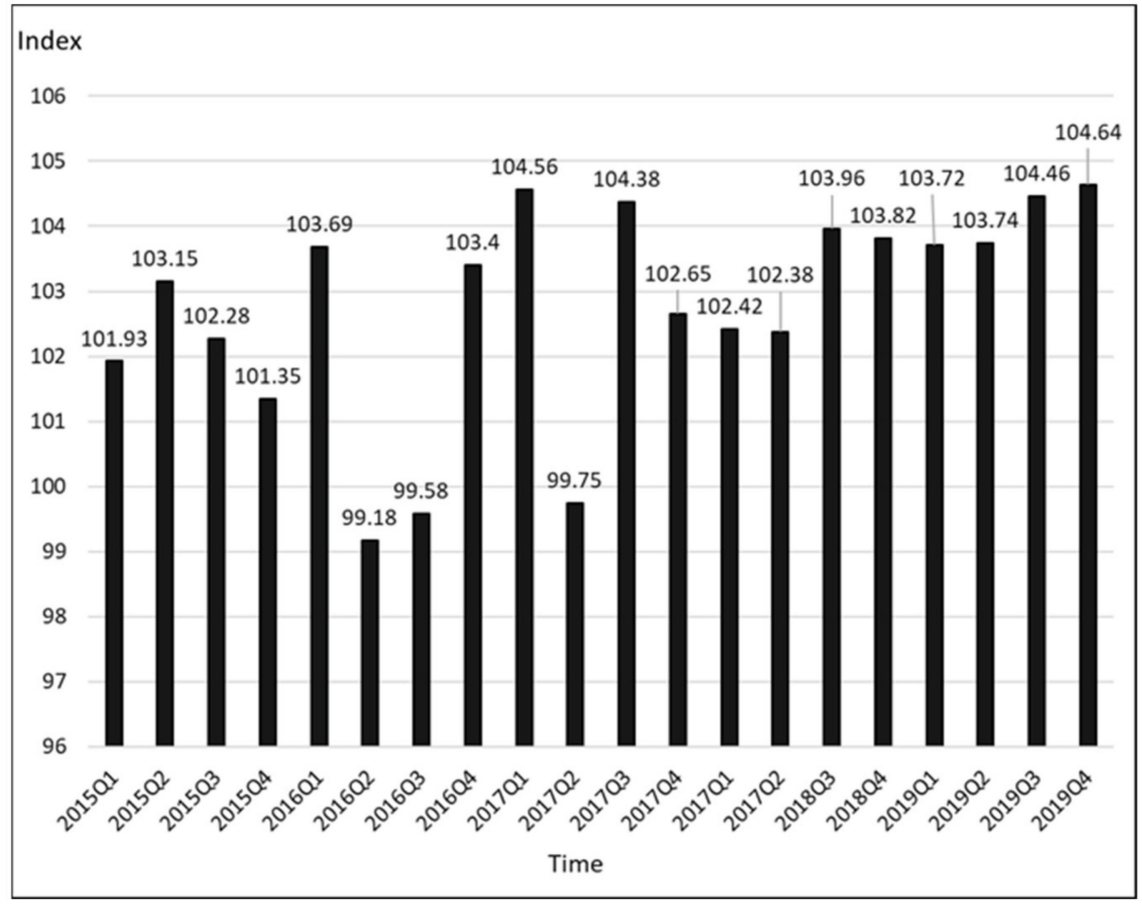

Figure 1. Taoyuan district house price index from 2015 to 2019.

Total flight refers to the total number of flights taken off and landed at Taoyuan International Airport in the month of the transaction. Previous studies have shown that the 
number of flights and noise has a positive relationship [40,41]; therefore, this study expects the total number of flights and the total house prices to negatively correlate.

- The direct noise value from the monitoring station (VMS)

The noise value of the monitoring station is used to record the $\mathrm{dB}$ Ldn in the noise control zone. It is the recording of the noise profile of single flyover events over a defined period $(24 \mathrm{~h})$, which can be combined and averaged to arrive at the Ldn with an appropriate weighting of night-time events. The publicly available noise data used in this paper have excluded non-aviation noise as much as possible. Aviation noise sampling methods and instruments comply with relevant regulations and national standards. In addition to strictly comparing the radar trajectories of the flight service center, the trigger level is adjusted according to the background noise, and the quarterly report is submitted to the Environmental Protection Bureau of Executive Yuan for review and reported to the Taoyuan City Government. This study used the monthly average of monitoring stations. The noise monitoring value of each house is the monthly average noise value of the nearest monitoring station in the trading month. In the past literatures, this variable was used as the independent variable, but in this research it will be used as a comparison with the estimated noise value (VE).

- $\quad$ Estimated noise value (VE)

Aviation noise will attenuate as the distance from the flight track increases [42], and monitoring equipment of the monitoring station is rigorously calibrated regularly to maintain data accuracy; however, the noise collecting equipment has physical limitations. Additionally, all transaction samples within a certain range received the same noise value/influence, which may be unreasonable. To avoid the problems caused by the location and distance restrictions of the noise monitoring stations, an estimated noise value for each transaction sample was generated.

When sound propagates in air, there are two types of sound attenuation. The first type is when the sound gradually moves away from the sound source, the sound wave energy spreads and produces a distance attenuation. The other type is the attenuation that is absorbed when sound waves propagate in the air or near the ground surface owing to the viscosity or heat conduction of the air, and the sound absorption of the ground surface [43]. In the free field, the linear sound source decay and distance formula $[44,45]$ is:

$$
\text { Linear noise source : } \Delta L=10 \times \log \frac{\gamma_{2}}{\gamma_{1}}
$$

where $\gamma_{1}$ and $\gamma_{2}$ indicate different distances from the noise source.

A linear sound source composed of countless non-directional points radiates sound waves outward cylindrically with a linear sound source as the axis. For example, if the noise at a distance of $10 \mathrm{~m}$ from the linear sound source is $100 \mathrm{~dB}$, the noise value at a distance of $100 \mathrm{~m}$ is approximately $90 \mathrm{~dB}$ :

$$
\Delta L=10 \times \log \frac{\gamma_{2}}{\gamma_{1}}, \Delta L=10 \times \log \frac{100}{10}, 100-10=90(\mathrm{~dB})
$$

Regardless of weather and building barriers, this study innovatively takes the extension of the glideslope at both ends of the runway centerline as the reference line (runway 05L/R 10 miles each and runway 23R/L 5 miles each parallel red line; blue dots represent noise monitoring station positions), as shown in Figure 2. This study uses Google Maps to measure the vertical distance between the trading house section and the baseline, before measuring the vertical distance between the nearest monitoring station and the baseline. Finally, this study considers the actual measured noise value in the noise and distance formula to obtain the estimated noise value. 


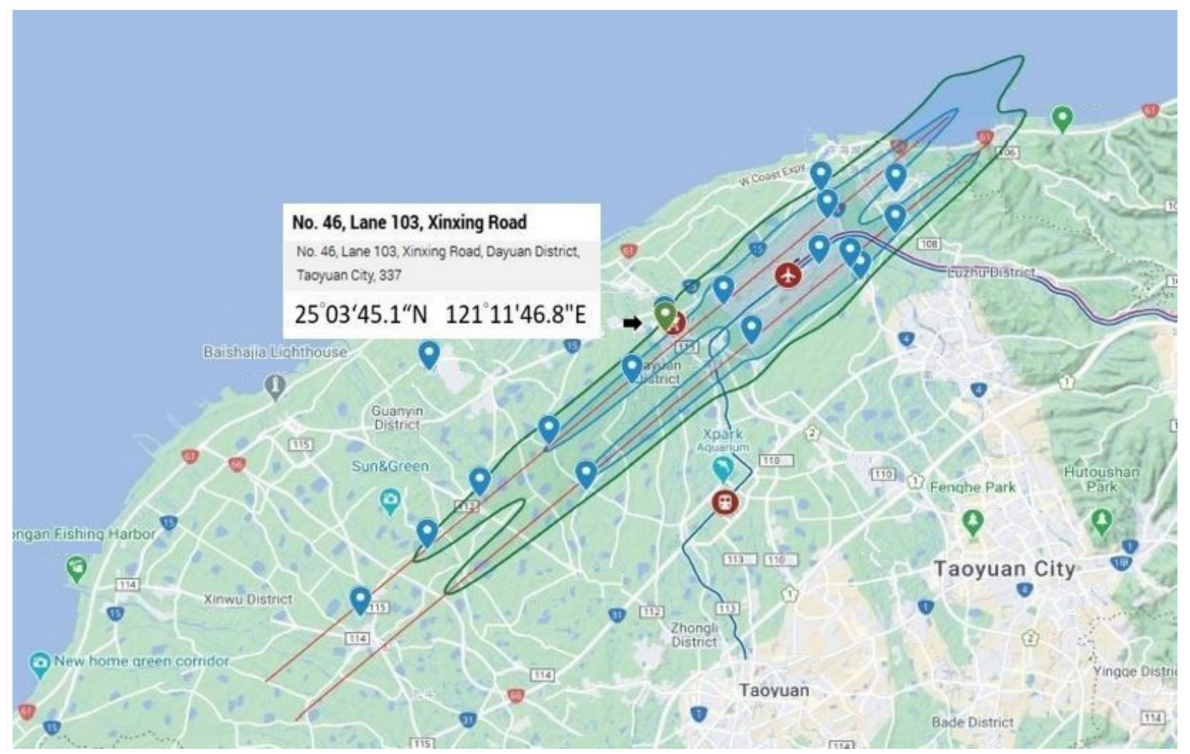

Figure 2. Runway baseline and geographic location map of 18 monitoring stations.

For example, the trading data considered were recorded on October 2018, as shown in Figure 3. It is at No. 46, Xinxing Road Tianxin, Dayuan, located in the 60-64 dB contour noise zone. Its distance to the Runway 05L/23R extension line is approximately $442 \mathrm{~m}$ and the Dayuan office is the nearest noise monitoring station to the trading house. The distance from the Dayuan office to the Runway 05L/23R extension line was approximately $578 \mathrm{~m}$. The monthly average noise of the Dayuan office monitoring station in October 2018 using Equation (4) was $59.9 \mathrm{~dB}$, and the estimated noise value for the trading house is $61.0651 \mathrm{~dB}$.

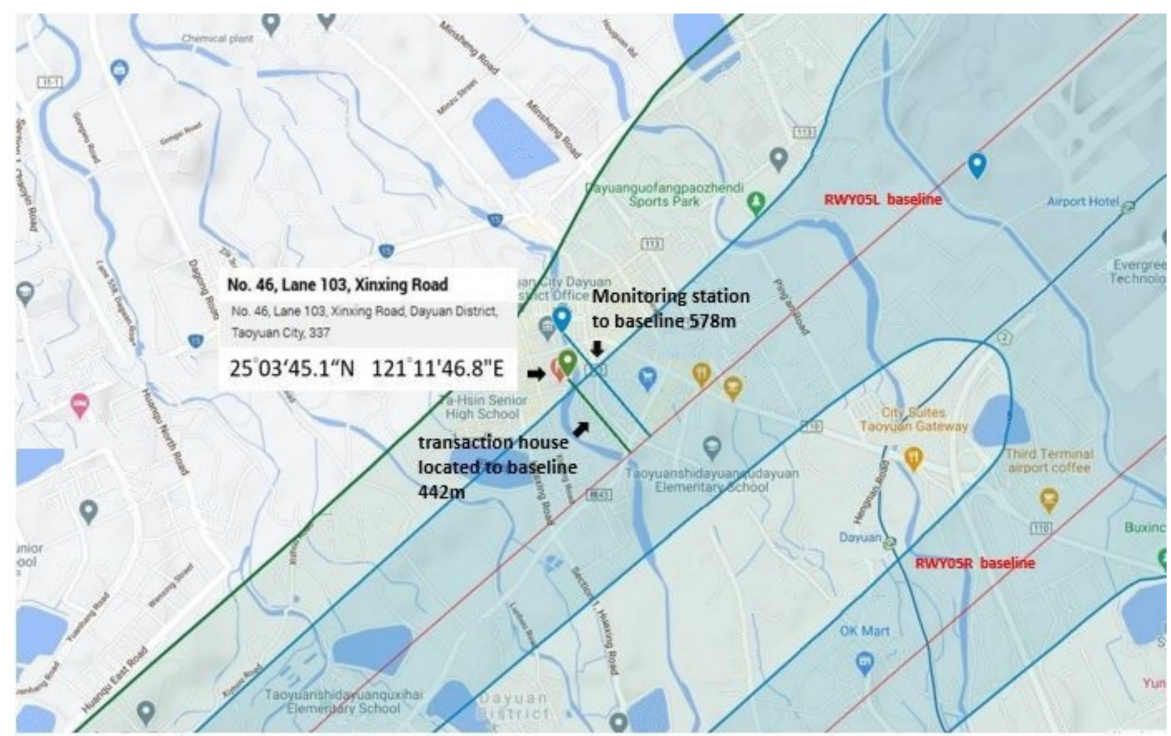

Figure 3. An example of the calculation of estimated noise value of a house.

- $\quad$ Noise reward fund (NR)

The NR refers to the monthly amount of reward funds distributed to a house. Taoyuan International Airport allocates a certain percentage of the landing fee annually as NR. The scope of the feedback area is based on the noise contour map, and the airport noise zones are divided by the $60-64 \mathrm{~dB}$ contour and $\geq 65 \mathrm{~dB}$ contour with distribution ratios of $5 \%$ and $25 \%$, respectively. According to the annual household statistics, get the average household noise reward fund in the month of housing transaction.

- $\quad$ Floor area (FA) 
FA refers to the total area registered for transferring the transaction target in square meters. The larger the area is, the higher the total price is [14], this is expected to be positively correlated with the total house price.

- $\quad$ House age (HA)

HA refers to the transaction target from the completion date. Generally, the house is older and the transaction price will be lower $[18,46]$, This study expects that the total house price and house age will be negatively correlated.

- House floor $(\mathrm{HF})$

HF refers to the floor in which the transaction target is located. Most of the expectations in the literature are positive because the first floor has the value of commercial benefits with a higher price. As a landscape advantage, the top floor has a higher price than other floors $[46,47]$. However, the residential area used in this study is an aviation noise area. According to the regulations issued by the Civil Aviation Administration of Taiwan, the height of the floor is restricted, and the higher floor is noisier. Therefore, the expectation of the study is that the total price of the house is negatively correlated with the floor, which is different from the literature.

- $\quad$ Distance to the public retail market (DTM)

DTM chooses the distance between the geographic location of the transaction target and the public retail market to enhance the representativeness of the neighborhood's characteristics. The closer the residence is to important commercial activities in the city center, the higher the price is. Since most of the aviation noise area is located in a large park area, this study considers the large park public retail market $\left(25^{\circ} 03^{\prime} 56.7^{\prime \prime} \mathrm{N} 121^{\circ} 11^{\prime} 55.0^{\prime \prime} \mathrm{E}\right.$, WGS84) as the target. The research assumes that the total house price is negatively correlated with the distance of the public retail market.

- $\quad$ Distance to High-Speed Rail station (DTR)

DTR refers to the distance between the location of the house and Taoyuan HSR station $\left(25^{\circ} 00^{\prime} 46.7^{\prime \prime} \mathrm{N} 121^{\circ} 12^{\prime} 53.2^{\prime \prime} \mathrm{E}, \mathrm{WGS} 84\right)$, and also refers to the distance between the geographic location of the transaction target and Taoyuan HSR station. Considering the convenience of transportation, the transaction price of houses is positively affected by the benefits of nearby transportation and the total house prices will increase. This research expects an inverse relationship between the total house prices and the distance from the HSR station.

- $\quad$ Distance to Taoyuan international airport (DTA)

The distance between the location of the house and Taoyuan International Airport refers to the distance between the geographic location of the transaction target and Taoyuan International Airport $\left(25^{\circ} 04^{\prime} 50.3^{\prime \prime} \mathrm{N} 121^{\circ} 14^{\prime} 02.2^{\prime \prime} \mathrm{E}, \mathrm{WGS} 84\right)$. The closer the residence is to the airport, the greater the noise and the lower the price is. This study expects the total price of a house to be positively correlated with the distance to the airport.

\section{Empirical Results}

The aviation noise values used in this research were collected from Taoyuan International Airport's Aviation Noise Monitoring Report from 2015 to 2019 and Taoyuan City Government Environmental Protection Bureau's noise website [48] The values related to the real estate, such as the location, price, transaction date, and square meters of the house were collected from the Ministry of the Interior, Taiwan [49]. Data presented in units of months after processing. The data interval is based on the period from 1 January 2015 to 31 December 2019, with residential properties whose transaction price is not zero as the subject of this study, excluding parking space transactions; there were a total of 769 transactions in five years. The transaction samples shown in Figure 4 are distributed in relevant locations in the aviation noise area. 


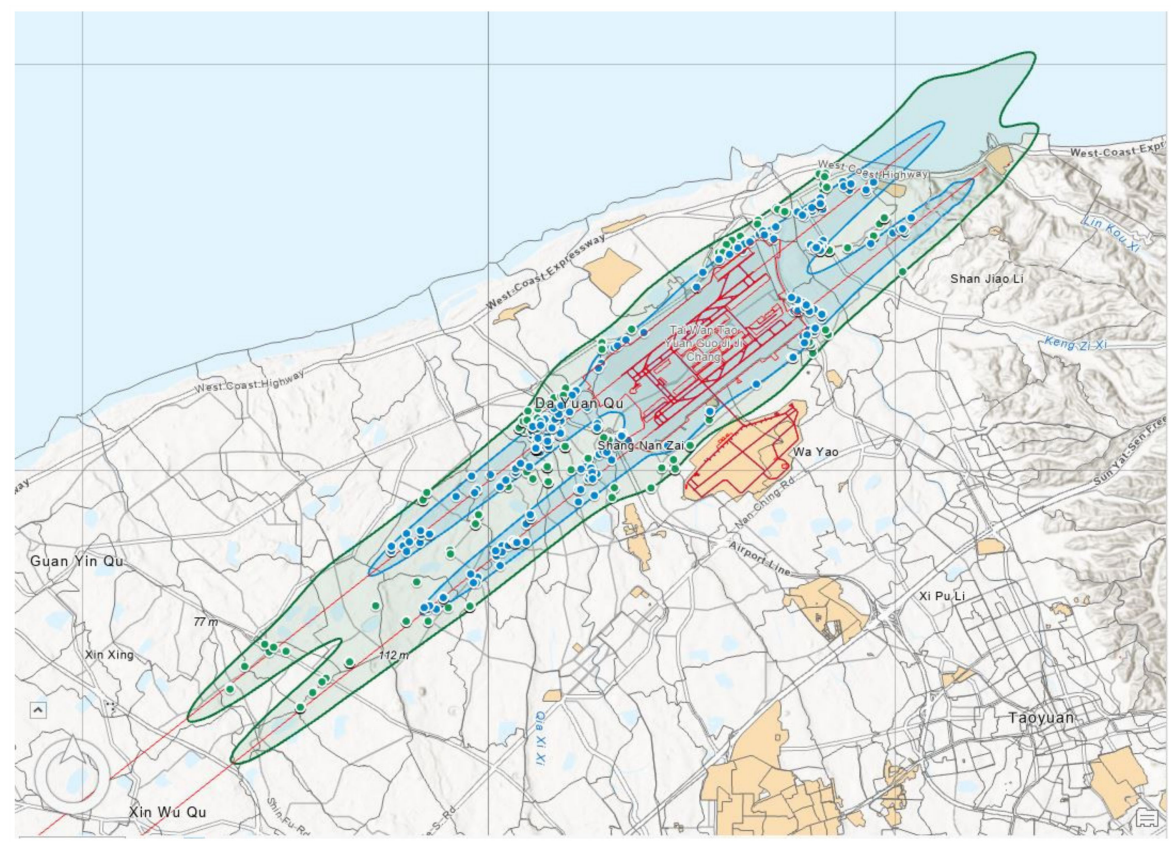

Figure 4. Transaction samples located in the aviation noise area of this study.

\subsection{Descriptive Statistics}

Table 1 presents the descriptive statistics of all the variables used in this study. The average ATP value in the 60-64 dB and $\geq 65 \mathrm{~dB}$ noise contour zones are USD 199,838, and USD 236,684, respectively. For the noise variables in the 60-64 dB and $\geq 65 \mathrm{~dB}$ zones, the average TF values are 20,824.12 and 20,769.04, respectively; the average VMS values are $66.36 \mathrm{~dB}$ and $67.02 \mathrm{~dB}$, respectively; the average VE values are $65.32 \mathrm{~dB}$ and $67.24 \mathrm{~dB}$, respectively; the average NR for the transaction is USD 1,114,122 and USD 1,085,800, respectively. Considering the residential variables in the $60-64 \mathrm{~dB}$ and $\geq 65 \mathrm{~dB}$ zones, the average FA values are $145.38 \mathrm{~m}^{2}$ and $158.53 \mathrm{~m}^{2}$, respectively; the average HA values are 19.13 years and 20.24 years, respectively; the average $\mathrm{HF}$ values of the two districts are 3.37 floors and 3.38 floors, respectively. Considering the location variables in the $60-64 \mathrm{~dB}$ and $\geq 65 \mathrm{~dB}$ zones, the average DTM is $9.34(\mathrm{~km})$ and $9.46(\mathrm{~km})$, respectively; the average DTRs are $6.04(\mathrm{~km})$ and $5.33(\mathrm{~km})$, respectively; the average DTA values are $5.35 \mathrm{~km}$ and $5.17 \mathrm{~km}$, respectively; the total number of samples in the $60-64 \mathrm{~dB}$ and $\geq 65 \mathrm{~dB}$ noise contour zones are 311 and 458 , respectively.

Table 1. Means and standard deviations of all variables.

\begin{tabular}{ccccc}
\hline \multirow{2}{*}{ Variables } & \multicolumn{2}{c}{ 60-64 dB Zone } & \multicolumn{2}{c}{$\geq \mathbf{6 5}$ dB Zone } \\
\cline { 2 - 5 } & Mean & Standard Deviation & Mean & Standard Deviation \\
\hline ATP (USD) & 199,839 & 116,611 & 236,684 & 199,952 \\
TF (flight) & $20,824.12$ & 1234.11 & $20,769.04$ & 6.34 \\
VMS (dB) & 66.36 & 5.65 & 67.02 & 6.80 \\
VE (dB) & 65.32 & 6.48 & 67.24 & $188,754.40$ \\
NR (USD) & $1,114,122$ & $206,450.10$ & $1,085,800$ & 87.18 \\
FA (m ${ }^{2}$ ) & 145.38 & 69.46 & 158.53 & 14.88 \\
HA (year) & 19.13 & 16.10 & 20.24 & 3.55 \\
HF (floor) & 3.37 & 1.64 & 3.38 & 3.33 \\
DTM (km) & 6.04 & 3.60 & 9.46 & 3.95 \\
DTR (km) & 9.34 & 3.53 & 5.17 & 2.07 \\
DTA (km) & 5.35 & 3.21 & & 458 \\
$n$ & & & & \\
\end{tabular}

Note: ATP, the adjusted total price of real estate; TF, total flights; VMS, the noise value directly from the monitoring station; the monitoring station; VE, the estimated noise value; NR, noise reward fund; FA, floor area; HA, house age; HF, house floor; DTM, distance to the public retail market; DTR, distance to High Speed Rail station; DTA, distance to Taoyuan international airport. 


\subsection{Analysis Results}

This study uses the traditional VMS and the proposed VE methods for comparing noise variables.

\subsubsection{The 60-64 dB Noise Contour Zone}

First, considering the noise value of the monitoring station as the independent variable, the TF, VMS, NR, FA, HA, HF, DTM, DTR, were used as independent variables, to the semi-log, inverse semi-log, and double-log models for the 60-64 dB noise contour zone. The adjusted R-square of the semi-log method is 0.5933 , the inverse semi-log model is 0.6065 , and the double-log model is 0.6246 , as shown in Table 2. The double-log model exhibited the best performance among these models.

Table 2. Analysis results of the 60-64 dB noise contour zone using VMS.

\begin{tabular}{ccccccc}
\hline \multirow{2}{*}{ Independent Variables } & \multicolumn{2}{c}{ Semi-Log } & \multicolumn{2}{c}{ Inverse Semi-Log } & \multicolumn{2}{c}{ Double Log } \\
\cline { 2 - 7 } & Coefficient & $\boldsymbol{p}$-Value & Coefficient & $\boldsymbol{p}$-Value & Coefficient & $\boldsymbol{p}$-Value \\
\hline constant term & 6.9088 & $0.0000^{* *}$ & 2551.1640 & 0.3460 & 7.4938 & 0.0560 \\
TF & 0.0000 & 0.9140 & -164.3492 & 0.7210 & 0.0963 & 0.8850 \\
VMS & $-\mathbf{0 . 0 0 7 1}$ & $\mathbf{0 . 0 9 5 0}$ & $-\mathbf{2 5 5 . 4 1 8 7}$ & $\mathbf{0 . 1 5 5 0}$ & $-\mathbf{0 . 5 1 3 4}$ & $\mathbf{0 . 0 4 9 0} * *$ \\
NR & 0.0000 & 0.6050 & -18.3837 & 0.9010 & -0.0874 & 0.6810 \\
FA & 0.0178 & $0.0000^{* *}$ & 535.6823 & $0.0000^{* *}$ & 0.7686 & $0.0000^{* *}$ \\
HA & -0.0073 & $0.0000^{* *}$ & -96.0894 & $0.0000^{* *}$ & -0.1524 & $0.0000^{* *}$ \\
HF & -0.0253 & 0.0940 & -134.4197 & $0.0000^{* *}$ & -0.1838 & $0.0000^{* *}$ \\
DTM & -0.0194 & $0.0130^{* *}$ & -33.2955 & $0.0450 * *$ & -0.0687 & $0.0040 * *$ \\
DTR & -0.0232 & $0.0010^{* *}$ & -95.6843 & $0.0190 * *$ & -0.1524 & $0.0100 * *$ \\
DTA & -0.0302 & $0.0000^{* *}$ & -155.1322 & $0.0000 * *$ & -0.2124 & $0.0000 * *$ \\
$R^{2}$ & \multicolumn{2}{c}{0.6051} & & 0.6179 & & 0.6355 \\
Adj- $R^{2}$ & \multicolumn{2}{c}{0.5933} & & 0.6065 & & $\mathbf{0 . 6 2 4 6}$ \\
\hline
\end{tabular}

** Significance Level of 0.05 . Note: ATP, the adjusted total price of real estate; TF, total flights; VMS, the noise value directly from the monitoring station; NR, noise reward fund; FA, floor area; HA, house age; HF, house floor; DTM, distance to the public retail market; DTR, distance to High Speed Rail station; DTA, distance to Taoyuan international airport.

The new model results of replacing the VMS with the VE in the three models are presented in Table 3. The adjusted R-square of the semi-log model is 0.5990 , the inverse semi-log model is 0.6157 , and the double-log model is 0.6355 , as shown in Table 3 . The double-log model still exhibited the best performance among these models.

Table 3. Analysis results of the 60-64 dB noise contour zone using VE.

\begin{tabular}{ccccccc}
\hline \multirow{2}{*}{$\begin{array}{c}\text { Independent } \\
\text { Variables }\end{array}$} & \multicolumn{2}{c}{ Semi-Log } & \multicolumn{2}{c}{ Inverse Semi-Log } & \multicolumn{2}{c}{ Double Log } \\
\cline { 2 - 7 } & Coefficient & $p$-Value & Coefficient & $p$-Value & Coefficient & $p$-Value \\
\hline constant term & 7.1998 & $0.0000^{* *}$ & 3423.7440 & 0.2030 & 9.0214 & $0.0200^{* *}$ \\
TF & 0.0000 & 0.5860 & -296.5058 & 0.5020 & -0.1774 & 0.7800 \\
VE & $-\mathbf{0 . 0 0 9 5}$ & $\mathbf{0 . 0 0 8 0 * *}$ & $-\mathbf{4 5 0 . 0 4 4 4}$ & $\mathbf{0 . 0 0 3 0} * *$ & $-\mathbf{0 . 7 7 0 1}$ & $\mathbf{0 . 0 0 0 0} * *$ \\
NR & 0.0000 & 0.9920 & 54.6645 & 0.7080 & 0.0430 & 0.8380 \\
FA & 0.0173 & $0.0000^{* *}$ & 511.6846 & $0.0000^{* *}$ & 0.7319 & $0.0000^{* *}$ \\
HA & -0.0079 & $0.0000^{* *}$ & -101.3398 & $0.0000^{* *}$ & -0.1607 & $0.0000^{* *}$ \\
HF & -0.0203 & 0.1790 & -119.2131 & $0.0000^{* *}$ & -0.1587 & $0.0010^{* *}$ \\
DTM & -0.0165 & 0.0340 & -32.3120 & $0.0480^{* *}$ & -0.0661 & $0.0050^{* *}$ \\
DTR & -0.0202 & $0.0030^{* *}$ & -69.8722 & 0.0850 & -0.1063 & 0.0700 \\
DTA & -0.0297 & $0.0000^{* *}$ & -151.7705 & $0.0000^{* *}$ & -0.2046 & $0.0000 * *$ \\
$R^{2}$ & & 0.6107 & & 0.6268 & & 0.6461 \\
Adj- $R^{2}$ & & 0.5990 & & 0.6157 & & $\mathbf{0 . 6 3 5 5}$
\end{tabular}

** Significance Level of 0.05 . TF, total flights; VE, the estimated noise value; NR, noise reward fund; FA, floor area HA, house age; HF, house floor; DTM, distance to the public retail market; DTR, distance to High Speed Rail station; DTA, distance to Taoyuan international airport. 
Comparing the results of the two analyses, this study established that when the noise value of the VMS is used as the independent variable, it is insignificant under both the semi-log and inverse semi-log methods, which is inconsistent with the results of previous studies [12,14]; However, when the estimated aviation noise is used as an independent variable, it is a significant predictor in the semi-log, inverse semi-log, and double-log models for the 60-64 dB noise control zone.

\subsubsection{The $\geq 65 \mathrm{~dB}$ Noise Contour Zone}

The $\geq 65 \mathrm{~dB}$ noise contour zone was analyzed using the same method. The total house price was analyzed using the semi-log, inverse semi-log, and double-log models. The analysis results are shown in Table 4; the adjusted square of the semi-log, inverse semi-log, and double-log models are $0.6578,0.623$, and 0.6688 , respectively. The double-log model exhibited the best performance among these models. VMS was then replaced by VE in the three models, and the results are presented in Table 5. According to this table, the adjusted R square of the semi-log, inverse semi-log, and double-log models are 0.6620 , 0.6398 , and 0.6828 , respectively and the double-log model exhibits the best performance. Comparing the results of the two analyses, in the $\geq 65 \mathrm{~dB}$ noise contour zones, when the VMS is used as the independent variable, it is not significant in all three models. These results are inconsistent with the results of previous studies. When VE was used as the independent variable, it was a significant feature in all three models.

Table 4. Analysis results of the $\geq 65 \mathrm{~dB}$ noise contour zone using VMS.

\begin{tabular}{|c|c|c|c|c|c|c|}
\hline \multirow{2}{*}{$\begin{array}{l}\text { Independent } \\
\text { Variables }\end{array}$} & \multicolumn{2}{|c|}{ Semi-Log } & \multicolumn{2}{|c|}{ Inverse Semi-Log } & \multicolumn{2}{|c|}{ Double Log } \\
\hline & Coefficient & $p$-Value & Coefficient & $p$-Value & Coefficient & $p$-Value \\
\hline constant term & 7.2717 & $0.0000 * *$ & 7469.4550 & 0.0630 & 9.7636 & $0.0350 * *$ \\
\hline TF & 0.0000 & 0.3150 & -814.4839 & 0.2110 & -0.9650 & 0.1970 \\
\hline VMS & -0.0037 & 0.3130 & -320.7554 & 0.1180 & -0.3372 & 0.1530 \\
\hline NR & 0.0000 & 0.2370 & 81.4750 & 0.6820 & 0.3487 & 0.1270 \\
\hline FA & 0.0200 & $0.0000 * *$ & 736.8074 & $0.0000 * *$ & 0.8913 & $0.0000 * *$ \\
\hline HA & -0.0128 & $0.0000 * *$ & -150.2994 & $0.0000 * *$ & -0.2017 & $0.0000 * *$ \\
\hline $\mathrm{HF}$ & -0.0667 & $0.0000 * *$ & -270.5330 & $0.0000 * *$ & -0.2843 & $0.0000 * *$ \\
\hline DTM & -0.0249 & $0.0070 * *$ & -94.9867 & $0.0000 * *$ & -0.1209 & $0.0000 * *$ \\
\hline DTR & -0.0260 & $0.0010 * *$ & -151.9047 & $0.0070 * *$ & -0.2360 & $0.0000 * *$ \\
\hline DTA & -0.0549 & $0.0000 * *$ & -197.3671 & $0.0000 * *$ & -0.2170 & $0.0000 * *$ \\
\hline$R^{2}$ & \multicolumn{2}{|c|}{0.6646} & \multicolumn{2}{|c|}{0.6304} & \multicolumn{2}{|c|}{0.6754} \\
\hline $\mathrm{Adj}-R^{2}$ & \multicolumn{2}{|c|}{0.6578} & \multicolumn{2}{|c|}{0.6230} & \multicolumn{2}{|c|}{0.6688} \\
\hline
\end{tabular}

** Significance Level of 0.05 ; TF, total flights; VMS, the noise value directly from the monitoring station; NR, noise reward fund; FA, floor area; HA, house age; HF, house floor; DTM, distance to the public retail market; DTR, distance to High Speed Rail station; DTA, distance to Taoyuan international airport.

Table 5. Analysis results of the $\geq 65 \mathrm{~dB}$ noise contour zone using VE.

\begin{tabular}{|c|c|c|c|c|c|c|}
\hline \multirow{2}{*}{$\begin{array}{l}\text { Independent } \\
\text { Variables }\end{array}$} & \multicolumn{2}{|c|}{ Semi-Log } & \multicolumn{2}{|c|}{ Inverse Semi-Log } & \multicolumn{2}{|c|}{ Double Log } \\
\hline & Coefficient & $p$-Value & Coefficient & $p$-Value & Coefficient & $p$-Value \\
\hline constant term & 7.5379 & $0.0000^{* *}$ & 7588.7950 & 0.0540 & 9.8692 & 0.0290 \\
\hline TF & 0.0000 & 0.3230 & -658.9820 & 0.2930 & -0.7685 & 0.2860 \\
\hline $\mathrm{VE}$ & -0.0090 & $0.0110 * *$ & -903.1992 & $0.0000 * *$ & -1.0292 & $0.0000 * *$ \\
\hline NR & 0.0000 & 0.1870 & 125.8571 & 0.5160 & 0.3969 & 0.0750 \\
\hline FA & 0.0196 & $0.0000 * *$ & 706.7998 & $0.0000 * *$ & 0.8566 & $0.0000 * *$ \\
\hline HA & -0.0138 & $0.0000 * *$ & -167.2966 & $0.0000 * *$ & -0.2213 & $0.0000 * *$ \\
\hline $\mathrm{HF}$ & -0.0681 & $0.0000 * *$ & -272.9054 & $0.0000 * *$ & -0.2874 & $0.0000 * *$ \\
\hline DTM & -0.0247 & $0.0060 * *$ & -92.8842 & $0.0000 * *$ & -0.1191 & $0.0000 * *$ \\
\hline DTR & -0.0231 & $0.0030 * *$ & -116.1778 & $0.0370 * *$ & -0.1944 & $0.0020 * *$ \\
\hline DTA & -0.0455 & $0.0000 * *$ & -141.1679 & $0.0020 * *$ & -0.1525 & $0.0040 * *$ \\
\hline$R^{2}$ & \multicolumn{2}{|c|}{0.6686} & \multicolumn{2}{|c|}{0.6460} & \multicolumn{2}{|c|}{0.6891} \\
\hline $\operatorname{Adj}-R^{2}$ & \multicolumn{2}{|c|}{0.6620} & \multicolumn{2}{|c|}{0.6389} & \multicolumn{2}{|c|}{0.6828} \\
\hline
\end{tabular}

** Significance Level of 0.05 ; TF, total flights; VMS, the noise value directly from the monitoring station; NR, noise reward fund; FA, floor area; HA, house age; HF, house floor; DTM, distance to the public retail market; DTR, distance to High Speed Rail station; DTA, distance to Taoyuan international airport. 
Table 6 shows a comparison of the adjusted R-square for each model in the 60-64 $\mathrm{dB}$ and $\geq 65 \mathrm{~dB}$ noise contour zones. When the proposed VE is used as the independent variable, the suitability and explanatory power of all three hedonic price models was improved.

Table 6. Comparison of adjusted R-square for each model in the 60-64 dB and $\geq 65 \mathrm{~dB}$ noise contour zones.

\begin{tabular}{cccc}
\hline Noise Contour Zones & Semi-Log & Inverse Semi-Log & Double Log \\
\hline Adj- $R^{2} 60-64 \mathrm{~dB}$ (station) & 0.5933 & 0.6065 & 0.6246 \\
Adj- $R^{2} 60-64 \mathrm{~dB}$ (estimate) & 0.5990 & 0.6157 & 0.6355 \\
\hline Adj- $R^{2} \geq 65 \mathrm{~dB}$ (station) & 0.6578 & 0.6230 & 0.6688 \\
Adj- $R^{2} \geq 65 \mathrm{~dB}$ (estimate) & 0.6620 & 0.6389 & 0.6828 \\
\hline
\end{tabular}

Additionally, Tables 3-5 present the estimated coefficients of the VE possessing significant negative effects with stable results, which are different from the results of VMS. Moreover, the double-log model with estimated VE can generate the highest explanatory power in the 60-64 dB and $\geq 65 \mathrm{~dB}$ noise contour zones. Based on this model, it can be observed that the coefficient directions of all the noise variables, TF and VE, are consistent with the results of previous literature [15,25]. FA, HA, and HF are significant residential variables which are consistent with the expectations of this study and the literature. DTM, DTR, and DTA are significant location variables.

\subsection{Marginal Price of Features}

Two earlier studies found that the impact of the marginal price of noise features can represent willingness-to-pay to avoid airport noise [50,51]. As the double-log models in both the $60-64 \mathrm{~dB}$ and $\geq 65 \mathrm{~dB}$ noise contour zones are the optimal models with the highest adjusted R-square values, the regression coefficients of the models can be used to estimate the marginal price of each feature or explanation variable. The double-log model represents the extent to which the estimated price changes with the percentage change of a certain characteristic while maintaining the other quality characteristics as unchanged. Applying this relationship transformation, the calculation formula for the marginal price of each feature in the double-log model is [52]:

$$
p_{\mathrm{i}}=\frac{\partial \mathrm{S}}{\partial x_{\mathrm{i}}}=\hat{\gamma}\left(\frac{S}{X_{i}}\right)
$$

where $p_{\mathrm{i}}$ is the change in value of the house due to the incremental unit, $\hat{\gamma}$ is the estimated coefficient of $\ln X_{i}$ in the hedonic regression, $\mathrm{S}$ is the market value or sale price of the house, and $X_{i}$ is the quantity.

Table 7 shows the marginal prices of each feature used in the double-log models for the $60-64 \mathrm{~dB}$ and $\geq 65 \mathrm{~dB}$ noise contour zones. It can be seen from the Table 7 that in the 60-64 $\mathrm{dB}$ noise contour zone, the house value with a decline of approximately $2356.02 \mathrm{USD} / \mathrm{dB}$ increase; the house value decreases by $3622.78 \mathrm{USD} / \mathrm{dB}$ in the $\geq 65 \mathrm{~dB}$ noise contour zone. 
Table 7. Marginal price of each feature used in the double-log models in the 60-64 $\mathrm{dB}$ and $\geq 65 \mathrm{~dB}$ noise contour zones.

\begin{tabular}{ccccc}
\hline \multirow{2}{*}{ Variable } & \multicolumn{2}{c}{ 60-64 dB Zone } & \multicolumn{2}{c}{$\geq \mathbf{6 5} \mathrm{dB}$ Zone } \\
\cline { 2 - 5 } & Coefficient & Marginal Price (USD) & Coefficient & Marginal Price (USD) \\
\hline TF & -0.1774 & -1.7024 & -0.7685 & -8.7578 \\
VE & -0.7701 & -2356.03 & -1.0292 & -3622.79 \\
NR & 0.0430 & 0.000238 & 0.3969 & 0.002677 \\
FA & 0.7319 & 3325.65 & 0.8566 & 4228.25 \\
HA & -0.1607 & -1678.73 & -0.2213 & -2587.86 \\
HF & -0.1587 & -9410.82 & -0.2874 & -20125.26 \\
DTM & -0.0661 & -2186.98 & -0.1191 & -5288.78 \\
DTR & -0.1063 & -2274.40 & -0.1944 & -4863.81 \\
DTA & -0.2046 & -7642.44 & -0.1525 & -6981.53 \\
\hline
\end{tabular}

$\mathrm{TF}$, total flights; VE, the estimated noise value; NR, noise reward fund; FA, floor area; HA, house age; HF, house floor; DTM, distance to the public retail market; DTR, distance to High Speed Rail station; DTA, distance to Taoyuan international airport.

\section{Discussion}

As mentioned earlier, the double-log hedonic price model using the proposed estimated aviation noise as an independent variable can generate a better model than directly using the noise value from the monitoring station in the $60-64 \mathrm{~dB}$ and $\geq 65 \mathrm{~dB}$ noise contour regions. Detailed information of the models is also shown in Table 7. According to Table 7, the influence of significant features on the target variable in the $60-64 \mathrm{~dB}$ and $\geq 65 \mathrm{~dB}$ noise contour zones are compared and discussed.

The regression coefficients of TF are -0.1774 and -0.7685 for the $60-64 \mathrm{~dB}$ and $\geq 65 \mathrm{~dB}$ zones, respectively. This indicates an inverse relationship of TF with house prices, establishing that the higher the total number of flights is, the lower the house price is. This suggests that the result is consistent with expectations. Since it is insignificant, the TF change in monthly transactions may not affect the house prices relative to the noise value.

Considering VE, the regression coefficients were -0.7701 and -1.0292 for the $60-64 \mathrm{~dB}$ and $\geq 65 \mathrm{~dB}$ zones, respectively. The price is negatively affected at a significant level. This represents an increase in noise value and a decrease in house prices, indicating that aviation noise adversely influences house prices and increases externality costs. This is confirmed in the research expectation and the same conclusions as in most previous studies. This confirms the potential of the new valuation method proposed in this study. It is practical, effective and confirms that the greater the aviation noise is, the greater the negative impact of depreciation is.

From the perspective of noise cost, the government is pursuing the goal of maximizing total social welfare or minimizing administrative costs. If the order of the improvement plan focuses on total social welfare, the order of relocation and construction of the airport can be evaluated first; if the increase in external charges is considered for trends and administrative costs, it is more appropriate to control or subsidize [35]. As for the policy subsidy variables in this study, the regression coefficients of the NR in the $60-64 \mathrm{~dB}$ and $\geq 65 \mathrm{~dB}$ noise contour zones are 0.043 and 0.397 , respectively. Although these values are positively correlated, they are not statistically significant, and there is no direct relationship between the level of house price changes and noise compensation in areas affected by aviation noise. This indicates that the current compensation policy is appropriate and has generated a trend and effect of internalization of external costs to achieve the comprehensive benefits of environmental protection, while developing the aviation industry.

The direction of the FA and HA were consistent with the results of the relevant literature and reached a significant level. The regression coefficients of the FA in the $60-64 \mathrm{~dB}$ and $\geq 65 \mathrm{~dB}$ noise contour zones are 0.7319 and 0.8566 , respectively. This indicates that the larger the used area, the higher the price; this is consistent with empirical judgments. The price elasticity of houses in the $\geq 65 \mathrm{~dB}$ zone is greater than that in the $60-64 \mathrm{~dB}$ zone. 
In terms of HA, as the house becomes older, the internal equipment and various structures of the building will become increasingly obsolete, which affects the transaction price of the house. The regression coefficients of HA in the 60-64 dB and $\geq 65 \mathrm{~dB}$ noise contour zones were -0.1607 and -0.2213 , respectively. There is a negative relationship, which indicates that the greater the HA, the lower the value of the building; this result is consistent with expectations.

The regression coefficients of the HF in this study are -0.1587 and -0.2874 for the 60-64 $\mathrm{dB}$ and $\geq 65 \mathrm{~dB}$ zones, respectively, and they are significant. This shows that the floor height has a negative impact on house prices, which is different from general empirical judgments, but it conforms to the flight noise area house price characteristics [16,27]. The buildings in the noise area are affected by the restrictions of government regulations, as the aircraft height is low during the takeoff and landing phases. The source of noise is in the air; hence, the higher the total floors, the greater the impact of aviation noise. The HF variable shows that the higher the floor, the lower the price.

The regression coefficients of the DTM are -0.0661 and -0.1191 in the $60-64 \mathrm{~dB}$ and $\geq 65 \mathrm{~dB}$ zones, which indicates that the distance between the housing location and the public market is shorter, the living function is better, and the house price is higher.

Considering the DTR, the regression coefficient of the $\geq 65 \mathrm{~dB}$ noise contour zone is -0.1944 , showing a negative relationship with house prices and reaching a significant level. The shorter the distance between representatives and important transportation facilities, the higher the house price. These results are consistent with the expectations of this study. However, the regression coefficient in the 60-64 dB area was -0.1063 , which was insignificant. This may be attributed to most of the residents of Dayuan using private transportation, as the HSR is not the only mode of travel. The distance coefficient and house price of the HSR stations were insignificant. Additionally, because the geographical location of the Dayuan public market is in the 60-64 dB noise contour zone of the township center, it also presents the characteristics of traffic accessibility and life functions, which may lead to the effect of traffic accessibility within the DTR becoming insignificant.

According to past literature, the relationship between the distance of the house transaction sample to the airport and the house price, the noise of flight and the prohibition and restriction of the surrounding land have a certain negative detrimental effect on house prices, but they may still appear to be different because of different regions. In this study, the regression coefficients of the DTA in the $60-64 \mathrm{~dB}$ and $\geq 65 \mathrm{~dB}$ noise contour zones were -0.2046 and -0.1525 , respectively, which showed a negative relationship with house prices and reached a significant level. Being closer to the airport, the housing transaction samples being affected by the convenience of airport transportation, convenience of surrounding living functions, and the proximity to the Dayuan township center business district (the shortest straight-line distance between the retail market and the airport is $1.4 \mathrm{~km}$ ) are possible reasons for the inverse relationship between the two districts and house prices. The distance surpassed the negative externalities caused by aircraft noise and land construction prohibition laws to increase the price elasticity of houses in the 60-64 $\mathrm{dB}$ noise contour zone as compared to that in the $\geq 65 \mathrm{~dB}$ noise contour zone.

\section{Conclusions}

Pollution around airports, such as noise and air pollution, poses important environmental protection issues. Aviation industry-related activities cause unavoidable adverse environmental impacts and are major energy consumers. Aviation industry operations play an important role in economic development; development of airports is indistinguishable from economic development. Ensuring appropriate environmental management and sustainable development have become important issues recently. Considering the goals of sustainable development, airport authorities are making sustained efforts to maintain a tranquil environment and improve the quality of life of residents around airports.

This study evaluates the relationship between the impact of aviation noise on housing prices based on house prices. We proposed two novel independent variables, the estimated 
aviation noise value and noise reward fund features in the semi-log, inverse semi-log, and double-log models, for constructing effective hedonic price models. The actual noise monitoring data of Taiwan Taoyuan International Airport from 2015 to 2019 and the housing transaction data in the 60-64 dB Ldn and $\geq 65 \mathrm{~dB}$ Ldn noise contour zones of the airport were collected and used.

The empirical results show that the use of estimated aviation noise as the independent variable instead of the noise value directly from the monitoring station improved the suitability or interpretation of all models. Among all the constructed models, the double$\log$ model with the estimated aviation noise variables optimally represents the 60-64 dB and $\geq 65 \mathrm{~dB}$ zones and is the most suitable model for this study.

Considering the double-log model, this study found that aviation noise has a statistically significant impact on house prices in the $60-64 \mathrm{~dB}$ and $\geq 65 \mathrm{~dB}$ zones. The rate of decline in house prices is approximately USD 2356.02 and USD $3622.78 / \mathrm{dB}$ in the $60-64 \mathrm{~dB}$ and $\geq 65 \mathrm{~dB}$ zones, respectively. The total number of flights and noise reward funds had no significant impact. The noise reward fund having no impact indicates that the current subsidy method has been maintained at an appropriate level. The total floor area and house prices show a significant positive relationship; the age of the house and the total floors have a significant negative relationship with house prices. Except for the insignificant distance from the HSR station in the 60-64 dB zone, the distance from the public market and the airport has a significant negative impact.

This research focuses on the relationship between the impact of Taoyuan International Airport noise on house prices. To simplify the expression of the impact of residential variables and the availability of data collection, this study only considered noise-related factors; limited residential variables were considered. More residential- and/or noise-related attributes can be considered to evaluate the impact of aviation noise on housing prices from different perspectives can be one of future research directions. For the estimation of the noises heard in houses located near airports, the methods introduced in this study may be supplemented by referring to the noise contours of airports. Nonetheless, because a noise contour contains simulated/estimated noise values obtained from multiple sources of information (e.g., case information about airport conditions, aircraft types, operational parameters, the geometry between an observer/flight-segment pair, and noise metric information), during the assessment of house noise values, simulated noise values must be adjusted after considering several types of data. If effective house noise estimates can be obtained from noise contours, the use of noise contours to discuss the issues, such as the most appropriate time for evaluating noise effects, whether incidents involving higher specific Lmax values are superior to Ldn in determining noise effects, and when noise stops influencing house prices, can be considered as other future research directions, which will contribute toward enhancing airport noise control and land use planning.

Author Contributions: Conceptualization, writing—original draft preparation, writing—review and editing H.-C.T. and C.-J.L. All authors have read and agreed to the published version of the manuscript.

Funding: This research received no external funding.

Institutional Review Board Statement: Not applicable.

Informed Consent Statement: Not applicable.

Data Availability Statement: Not applicable.

Acknowledgments: The authors wish to express their sincere gratitude to the journal editor and the anonymous reviewers who spent their valued time to provide constructive comments and assistance to improve the quality of this paper. This work is partially supported by Ministry of Science and Technology, Taiwan (110-2221-E-030 -010 to C.-J.L.) and Fu Jen Catholic University (A0110181 to C.-J.L.).

Conflicts of Interest: The authors declare no conflict of interest. 


\section{References}

1. Muzet, A. Environmental noise, sleep and health. Sleep Med. Rev. 2007, 11, 135-142. [CrossRef] [PubMed]

2. Schreckenberg, D.; Meis, M.; Kahl, C.; Peschel, C.; Eikmann, T. Aircraft Noise and Quality of Life around Frankfurt Airport. Int. J. Environ. Res. Public Health 2010, 7, 3382-3405. [CrossRef] [PubMed]

3. Organization W.H.O. Environmental Noise Guidelines for the European Region. 2018. Available online: https://apps.who.int/ iris/bitstream/handle/10665/279952/9789289053563-eng.pdf (accessed on 9 December 2021).

4. Eriksson, C.; Pershagen, G.; Nilsson, M. Biological Mechanisms Related to Cardiovascular and Metabolic Effects by Environmental Noise; WHO Regional Office for Europe: Copenhagen, Denmark, 2018.

5. $\quad$ Dratva, J.; Phuleria, H.C.; Foraster, M.; Gaspoz, J.-M.; Keidel, D.; Künzli, N.; Liu, L.-J.S.; Pons, M.; Zemp, E.; Gerbase, M.W. Transportation noise and blood pressure in a population-based sample of adults. Environ. Health Perspect. 2012, 120, 50-55. [CrossRef] [PubMed]

6. Babisch, W.; Beule, B.; Schust, M.; Kersten, N.; Ising, H. Traffic noise and risk of myocardial infarction. Epidemiology 2005, 16, 33-40. [CrossRef] [PubMed]

7. Tofield, A. Air pollution and traffic noise effect on blood pressure. Eur. Heart J. 2017, 38, 71-72. [CrossRef]

8. Rojek, M.; Rajzer, M.; Pizon, T.; Skalski, P.; Czarnecka, D. PP. LB03. 06: The Effect of Aircraft Noise Exposure on Blood Pressure and Asymptomatic Organ Damage. J. Hypertens. 2015, 33, e518. [CrossRef]

9. Ozkurt, N.; Hamamci, S.F.; Sari, D. Estimation of airport noise impacts on public health. A case study of Izmir Adnan Menderes Airport. Transp. Res. Part D: Transp. Environ. 2015, 36, 152-159. [CrossRef]

10. Seidler, A.L.; Hegewald, J.; Schubert, M.; Weihofen, V.M.; Wagner, M.; Dröge, P.; Swart, E.; Zeeb, H.; Seidler, A. The Effect of Aircraft, Road, and Railway Traffic Noise on Stroke-Results of a Case-Control Study Based on Secondary Data. Noise Health 2018, $20,152$.

11. Saucy, A.; Schäffer, B.; Tangermann, L.; Vienneau, D.; Wunderli, J.-M.; Röösli, M. Does night-time aircraft noise trigger mortality? A case-crossover study on 24886 cardiovascular deaths. Eur. Heart J. 2020, 42, 835-843. [CrossRef]

12. Espey, M.; Lopez, H. The impact of airport noise and proximity on residential property values. Growth and Change 2000, 31, 408-419. [CrossRef]

13. Theebe, M.A. Planes, trains, and automobiles: The impact of traffic noise on house prices. J. Real Estate Financ. Econ. 2004, 28, 209-234. [CrossRef]

14. Püschel, R.; Evangelinos, C. Evaluating noise annoyance cost recovery at Düsseldorf International Airport. Transp. Res. Part D Transp. Environ. 2012, 17, 598-604. [CrossRef]

15. Suksmith, P.L.; Nitivattananon, V. Aviation impacts on property values and management: The case of Suvarnabhumi international airport. IATSS Res. 2015, 39, 58-71. [CrossRef]

16. Bishop, R.; Laing, K. Impact of Airport Noise on Residential Property Values: Cairns Airport. J. New Bus. Ideas Trends 2020, 18, $12-21$.

17. Cohen, J.P.; Coughlin, C.C. Spatial hedonic models of airport noise, proximity, and housing prices. J. Reg. Sci. 2008, 48, 859-878 [CrossRef]

18. Dekkers, J.; Weijschede, v.d.S.J.W. Monetary Valuation of Aircraft Noise: A Hedonic Analysis around Amsterdam Airport. Ecol. Econ. 2008, 68, 2850-2858. [CrossRef]

19. Bełej, M.; Cellmer, R.; Głuszak, M. The Impact of Airport Proximity on Single-Family House Prices—Evidence from Poland. Sustainability 2020, 12, 7928. [CrossRef]

20. Swoboda, A.; Nega, T.; Timm, M. Hedonic analysis over time and space: The case of house prices and traffic noise. J. Reg. Sci. 2015, 55, 644-670. [CrossRef]

21. Ridker, R.G.; Henning, J.A. The Determinants of Residential Property Values with Special Reference to Air Pollution. Rev. Econ. Stat. 1967, 49, 246-257. [CrossRef]

22. Huderek-Glapska, S.; Trojanek, R. The impact of aircraft noise on house prices. Int. J. Acad. Res. 2013, 5. [CrossRef]

23. Mense, A.; Kholodilin, K.A. Noise expectations and house prices: The reaction of property prices to an airport expansion. Ann. Reg. Sci. 2014, 52, 763-797. [CrossRef]

24. Trojanek, R.; Tanas, J.; Raslanas, S.; Banaitis, A. The Impact of Aircraft Noise on Housing Prices in Poznan. Sustainability 2017, 9, 2088. [CrossRef]

25. Trojanek, R.; Huderek-Glapska, S. Measuring the noise cost of aviation-The association between the Limited Use Area around Warsaw Chopin Airport and property values. J. Air Transp. Manag. 2018, 67, 103-114. [CrossRef]

26. Batóg, J.; Foryś, I.; Gaca, R.; Głuszak, M.; Konowalczuk, J. Investigating the impact of airport noise and land use restrictions on house prices: Evidence from selected regional airports in Poland. Sustainability 2019, 11, 412. [CrossRef]

27. Zheng, X.; Peng, W.; Hu, M. Airport noise and house prices: A quasi-experimental design study. Land Use Policy 2020, $90,104287$. [CrossRef]

28. Ma, W.; Zhang, A.; Zhang, Y.; Xu, S. The growing influence of low-cost carriers in Northeast Asia and its implications for a regional single aviation market. J. Air Transp. Manag. 2021, 91, 101994. [CrossRef]

29. Abdi, Y.; Li, X.; Càmara-Turull, X. Impact of Sustainability on Firm Value and Financial Performance in the Air Transport Industry. Sustainability 2020, 12, 9957. [CrossRef] 
30. McMillen, D.P. Airport expansions and property values: The case of Chicago O'Hare Airport. J. Urban Econ. 2004, 55, 627-640. [CrossRef]

31. Rosen, S. Hedonic prices and implicit markets: Product differentiation in pure competition. J. Political Econ. 1974, 82, 34-55. [CrossRef]

32. Benefield, J.; Sirmans, G.S. The influence of contingent closing costs on sale price, time on market, and probability of sale. J. Hous. Res. 2009, 18, 121-142. [CrossRef]

33. Ganic, E.M.; Netjasov, F.; Babic, O. Analysis of noise abatement measures on European airports. Appl. Acoust. 2015, 92, 115-123 [CrossRef]

34. Postorino, M.N.; Mantecchini, L. A systematic approach to assess the effectiveness of airport noise mitigation strategies. J. Air Transp. Manag. 2016, 50, 71-82. [CrossRef]

35. Lu, C.; Morrell, P. Determination and applications of environmental costs at different sized airports-aircraft noise and engine emissions. Transportation 2006, 33, 45-61. [CrossRef]

36. Pueschel, R.; Evangelinos, C. Airport noise footprints revisited: The impact of the cut-off value on noise costs. Z. Fuer Verk. 2016, $87,39-51$

37. Shiller, R.J. Irving fisher, debt deflation, and crises. J. Hist. Econ. Thought 2013, 35, 179-183. [CrossRef]

38. Dimand, R. Irving Fisher's The Purchasing Power of Money. Hist. Econ. Rev. 2011, 54, 131-143. [CrossRef]

39. Central Bank of the Republic of China (Taiwan). New Taiwan Dollar to US Dollar Exchange Rates Annual Historical. 2016. Available online: https:/ / www.cbc.gov.tw/tw/cp-2151-27029-FFC31-1.html (accessed on 3 April 2021).

40. Goldschagg, P.L. Using supplemental aircraft noise information to assist airport neighbours understand aircraft noise. Transp. Res. Part D: Transp. Environ. 2013, 21, 14-18. [CrossRef]

41. Hume, K.; Gregg, M.; Thomas, C.; Terranova, D. Complaints caused by aircraft operations: An assessment of annoyance by noise level and time of day. J. Air Transp. Manag. 2003, 9, 153-160. [CrossRef]

42. Federal Interagency Committee on Noise. Federal Agency Review of Selected Airport Noise Analysis Issues; Federal Interagency Committee on Noise: Washington, DC, USA, 1992.

43. Guillaume, G.; Gauvreau, B.; L'Hermite, P. Numerical study of the impact of vegetation coverings on sound levels and time decays in a canyon street model. Sci. Total Environ. 2015, 502, 22-30. [CrossRef]

44. Crocker, M.J. Noise and Noise Control: Volume 2; Crc Press: Boca Raton, FL, USA, 1982.

45. Novak, C. Case study of noise attenuation of large automotive manufacturing facility. Can. Acoust. 2002, 30, 23-29.

46. Cohen, J.P.; Coughlin, C.C. Changing noise levels and housing prices near the Atlanta airport. Growth and Change 2009, 40, 287-313. [CrossRef]

47. Ligus, M.; Peternek, P. Measuring structural, location and environmental effects: A hedonic analysis of housing market in Wroclaw, Poland. Procedia Soc. Behav. Sci. 2016, 220, 251-260. [CrossRef]

48. Real House Value Registry Scheme Service Network, Land Administration, Ministry of Interior, Taiwan. Available online: https:/ / lvr.land.moi.gov.tw / homePage.action (accessed on 6 March 2021).

49. Taoyuan City Government Environmental Protection Bureau Noise Website. Available online: www.noise.tydep.gov.tw (accessed on 6 March 2021).

50. Schipper, Y.; Nijkamp, P.; Rietveld, P. Why do aircraft noise value estimates differ? A meta-analysis. J. Air Transp. Manag. 1998, 4, 117-124. [CrossRef]

51. Nelson, J.P. Meta-analysis of airport noise and hedonic property values. J. Transp. Econ. Policy (JTEP) 2004, 38, 1-27.

52. Strom, S. Measurement in Public Choice; Palgrave Macmillan: London, UK, 1981. 